Epistēmēs Metron Logos, Issue 4

Epistēmēs Metron Logos Journal No 4 (2020)

DOI 10.12681/eml.23778 ISSN 2585-2973

\title{
The Universe and the limits of Knowledge: Bohm's Notion of the Implicate Order of Nature
}

Dimitrios Galanis-Kolintzas ${ }^{1}$

Abstract
According to Bohm the whole scientific description of the Universe is governed by
fragmentation of our perception of what reality is. Physics' tendency of acknowledging the
ultimate structure of matter in the elementary particles has caused a widespread
fragmentary view of the Universe. Thus, Physics seems to be unable to conceive the
"undivided wholeness of the universe" and to acknowledge in that Wholeness the common,
single bed of the whole of reality. According to Bohm that single bed of nature, Implicate
Order, is the single origin of both mind and matter. Inside the multidimensional Implicate
Order, a universal enfoldment of everything prevails. The Implicate Order coheres
deterministically to the Universe and the depths of its inwardness are totally unknown to
us, since we humans are part of its wholeness too. Physics as a science provides us only
with abstractive descriptions of the Universe, since science offers only abstractions from
reality. These abstractive descriptions are what constitute the Explicate Order of the
Universe. Thus, each belief we have that through the science of Physics we are able to
arrive at an ultimate deciphering of the Universe is inherently illusive. The science of
Physics can provide us with knowledge only in the fragmentary level of the Explicate, that
means analyzable, Order of the Universe recognizing its cognitive limits in front of the
Implicate Order. The laws that govern the Implicate Order of the Universe are unknowable
and unanalyzable by man and in the depths of these laws Bohm insists that a final truth
about reality cannot be fixed.

Keywords: fragmentation, Wholeness, Universe, Physics, elementary particles, Explicate Order, Implicate Order, common background, quantum physics, single origin of everything, universal enfoldment, mind, reality, Theory of Everything, Metaphysics

\footnotetext{
${ }^{1}$ National and Kapodistrian University of Athens, Department of Philosophy dimitriogal@gmail.com
} 


\section{Epistēmēs Metron Logos, Issue 4}

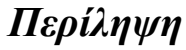

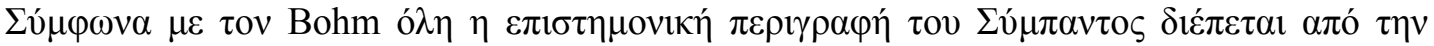

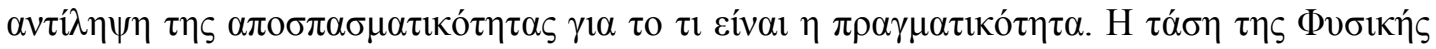

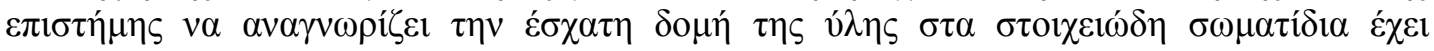

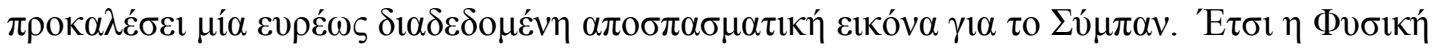

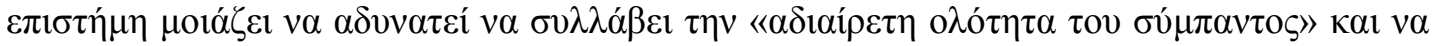

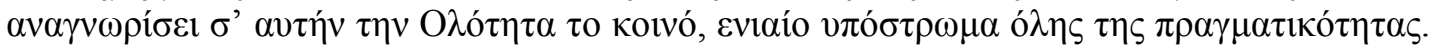

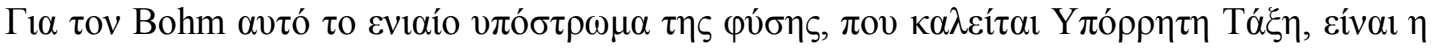

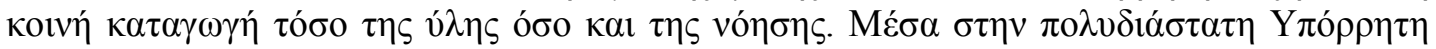

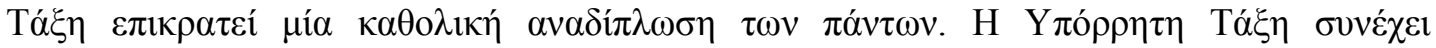

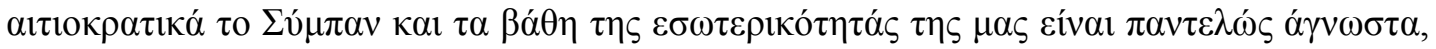

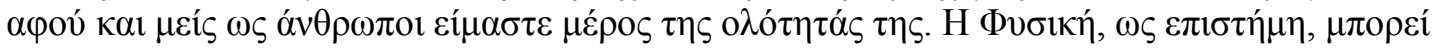

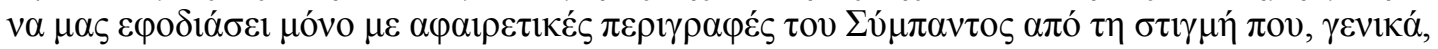

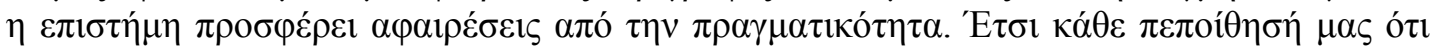

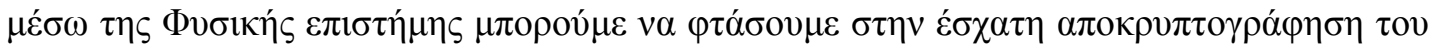

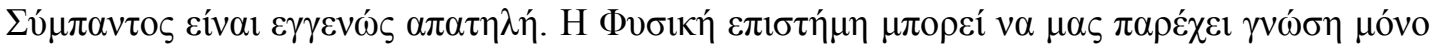

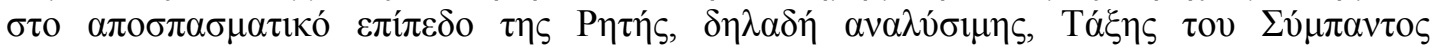

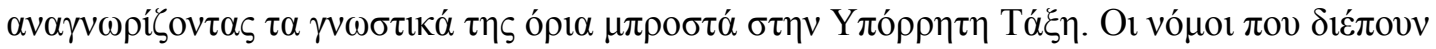

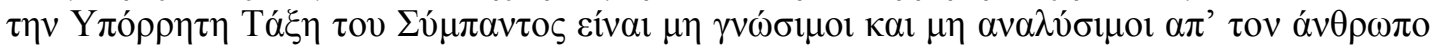

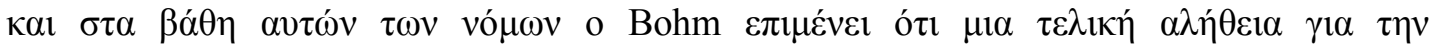

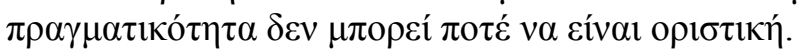

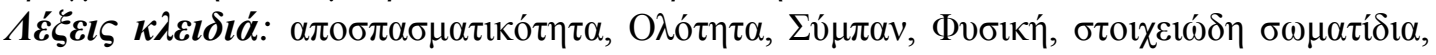

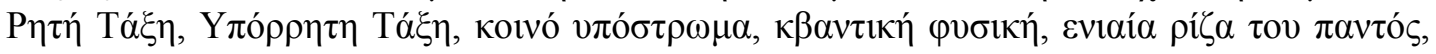

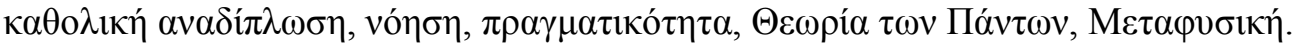

\section{Preface}

The objective of this article is to bring attention to the deep and prototypical thought on the nature of the Universe from one of the most renowned theoretical physicists and philosophers of the $20^{\text {th }}$ century who marked through his works the Modern Physics. It is about David Bohm and his monumental work by the title: "Wholeness and the Implicate Order". In this work Bohm explores a dynamic dialectic between the severe scientific knowledge of physics and the quasi-Metaphysics that the former may affirm. The terminal "quasi-Metaphysics" is a terminal of my own and it is proposed in this article so as to have a better understanding of Bohm's full vision about reality. Demonstrating the fragmentary nature of both sciences in general and the physical sciences in particular, Bohm attests in defense of a holistic perception of knowledge and reality (Bohm, 2002). He perceives two levels of knowledge and reality about nature: the Explicate and the Implicate Orders. He contends that the 


\section{Epistēmēs Metron Logos, Issue 4}

Implicate Order of nature is the fundamental energetic and connective bedrock of the Universe, the prime reality of the natural world which is mentally impenetrable by man (Bohm, 2002). We will firstly explain his thoughts on what the Implicate Order is and in what way it pervades the whole of natural reality. We will then be confronted by all the crucial questions that traditionally agonise the Western Philosophic and Scientific thought. One of them is the question of the relationship between matter and intellect, the question of if the Universe is deterministically ordered or not as well as the question of if the Implicate Order could be a divine creation. The first two questions are original ones that can be found in Bohm's own works (Bohm, 2002). The last one is a question of my own and I will try to answer it under the aspect of Bohm's notion of the Implicate Order of nature. In these questions arrives the terminal "quasi-Metaphysics" that, in my personal view, is emerged inside the notion of the Implicate Order. Because of these questions that remain open in different possible answers and approximations (Bohm, 2002), I give the perspective that Bohm's view of both material and mental aspects of reality might offer us a "quasi-Metaphysical" perspective of the whole reality.

The article is divided in two chapters. In the first chapter it will be explained the way in which Bohm conceives the Wholeness as the fundamental reality of the natural world as defined as the Implicate Order. It will also become clear how and why Bohm gave a grand defense for a non-fixed theory about reality. In the second chapter the connections between the Implicate and Explicate Orders will be clarified. We are going to understand how the Implicate Order could be seen as a single origin of everything in the Universe. This will include an explanation of how Bohm's conception of monism fits into discussions on the relationship between the material and mental aspects of reality. There can be found in general the questions that affirm the "quasi-Metaphysics" of Bohm's thought. An attempt will be made to comprehensively answer whether and to what extent the Implicate Order can be expressed in Modern Physics by a Theory of Superstrings, in the pursuit of a Theory of Everything. Thereafter it will be explained which is the deeper nature of the Implicate Order as the common "background" of the whole Universe (Bohm, 2002), and it will be investigated how far the depths of the Implicate Order can constitute a divine creation or not. Finally, by completing this presentation in the afterword, I will attempt to interpret Bohm's thoughts about the deeper nature of reality. 


\section{BOHM'S CONCEPTION OF WHOLENESS AND THE NOTION OF THE IMPLICATE ORDER OF NATURE}

\section{Fragmentation and Wholeness.}

According to Bohm (2002), the modern man lives a life full of fragmentation. That fragmentation becomes sensable in his way of thinking, and in the way in which he perceives himself and the world (Bohm, 2002). The dominance of fragmentation on the image that man has of himself and the world in which he lives is due to the fragmentation by which modern, scientific thought is mainly and inherently characterized (Bohm, 2002). Science divides reality into parts and therefore reality is organized as a cumulative classification of parts from which the sense of the whole has been missing (Bohm, 2002). Man affected by the fragmentation of science tends to see himself and the universe under the aspect of multiple fragmentation that the different sciences provide (Bohm, 2002). The knowledge of reality is divided up and with the knowledge of reality even the very reality as such is divided up. Reality occurs in the scientific thought as acknowledgement of parts of analysis and fragmentation therefore becomes the standard of approaching and knowing the reality (Bohm, 2002). Man finally experiences himself and the universe as an aggregate of divided parts. That sense of dissolution is about to be a deep-rooted delusion in the mind and is due to the common tendency of our thought to run fragmentarily (Bohm, 2002: 32). The dominance of fragmentation makes its presence everywhere sensible to the individual and to the society and it involves mental dangers. The outcome of that dominance is the feeling of despair, the different individual and social crises and the general confusion of mind (Bohm, 2002).

Inside that general experience of fragmentation the common worldview that Physics provides as a science is that of the breakdown of the divided elements of nature; that of the individuality of the elementary physical particles. Physicists get used to viewing the Universe as constructed by undivided monads that interact variously with each other (Bohm, 2002: 18-19). They speak about the elementary particles of matter and the laws governing their performance. It is about the Standard Model of elementary particles in modern Physics (Redhead, 2006). Thus the Universe in modern Physics is analyzed on the philosophical base of the traditional atomic theory and is usually seen under the aspect of an extreme mechanistic perception (Bohm, 2002). But the fact that physicists speak about the elementary particles and the fundamental forces of nature does not mean that they reach the ultimate deciphering of the Universe.

Under the dominance of the fragmentation modern man has a difficulty in methodically cultivating the sense of unity and the transcendentality of the whole 


\section{Epistēmēs Metron Logos, Issue 4}

(Bohm, 2002). But at the same time that he is struggling with perceiving the whole he is seeking by nature that Wholeness in which he can find a sense of unity of the divided elements and the chaos of theories. For Bohm (2002) the deceptive appearance of fragmentation is delusive. The Universe, and so on the very man as part of the Universe, is not pervaded by division but by unity (Bohm, 2002. Bohm \& Hiley, 1993). The reality for Bohm $(1984,2002)$ is Wholeness and not fragmentation, unity and not division.

Wholeness is the reality of the natural world (Bohm, 2002: 9, 32). Inside the Universe there is a whole reality which is "undivided and unanalysable" and this fact is acknowledged by man implicitly (Bohm, 2002: 10, 12, 14). Every piece of knowledge of the fragmentation declares implicitly its origin in that undivided Wholeness of the reality from which even the very consciousness as a premier act of intellectuality is not missed (Bohm, 2002). For Bohm (2002) the human intellect does not objectify the natural world, adjudging about the nature of reality, but she is even the same a part of that very reality for which she articulates reason and produces knowledge. The intellect does not trace the objectivity of Reality but it is part of that very Reality which it yearns for perceiving (Bohm, 2002: 76). Consequently the intellect is part of the Universe and has its origin in the common bed of the whole natural world. ${ }^{2}$ Inside that common, single bed of nature the distinction between matter and intellect is removed as soon as the depths of its inwardness are totally unknown to man (Bohm, 2002: 265-7). That almost mystic reality is the deeper reality of the Universe that Bohm names as the "Implicate Order" (Bohm, 2002: 225, 235) and we can say that it constitutes the single origin of everything.

\section{The Wholeness of the Universe is beyond our limited scientific insights and thoughts: a defense for a non-fixed theory about reality}

Unfortunately, man does not realize clearly that the scientific views of the natural world do not exhaust the objective reality of how the natural world really is in its deeper structure. ${ }^{3}$ In other words the scientific thought about the natural world does

\footnotetext{
${ }^{2}$ See:. Jeans, Sir J. (1993: 203-4, 210, 247-8, 276, 308), where it is cited the deeper "bedrock" of nature, which by being beyond the phenomena is cognitively impenetrable by the perceptual power of man.

${ }^{3}$ See: Jeans, Sir J. (1993: 253). Also: Nilsson, Nils J. (2014: 66), where is cited the aphoristic maxim of the physicist Niels Bohr: "It is wrong to think that the task of physics is to find out how nature $i s$. Physics concerns what we can say about nature...". In Bohm's notion of the Implicate and Explicate Order of nature the word " $i s$ " refers to the unknown depths of the Implicate Order that pervades the Universe (or the Multiverse) while the word "say" refers to the scientific explanation that the Explicate Order can offer us about the nature of the Universe (or the Multiverse).
} 


\section{Epistēmēs Metron Logos, Issue 4}

not coincide with the objective reality of the very natural world (Bohm, 2002). According to Bohm (1984, 2002), all the scientific views are not but partial, approximate aspects of the objective world that they try to describe. They are forms of insight subjected to constant alternation and improvement (Bohm, 2002: 6-7). ${ }^{4}$ Besides, the knowledge as such is a constant procedure and not a system of fixed truths (Bohm, 2002: 63, 80). When these insights receive the definite character of a fixed knowledge of how the natural world really is then they comprise the cause of the fragmentation (Bohm, 2002: 32). The root of the dominant fragmentation according to Bohm (2002) is the tendency of man to perceive his own thoughts about the natural world as fixed truths. The fixation in the fragmentation thus drags the man off the perception of the "undivided wholeness of the universe" (Bohm, 2002: 227, 262). ${ }^{5}$

Fragmentation goes together with the fixing of our insights, because all the scientific insights are limited (Bohm, 2002). The wholeness of reality is ever beyond our scientific insights and thoughts because our very insights and thoughts are parts of the whole reality in which they exist (Bohm, 2002). Reality is not exhausted by our thoughts (Bohm, 2002). Besides, scientific theories are just mental pictures of the natural world (Nilsson, 2014) and models of description of reality (Dear, 2007).

The scientific descriptions of the Universe are not then objective truths that correspond to the objective reality of the Universe (Bohm, 2002. Dear, 2007). They have a degree of truth but only in an approximate form (Bohm, 2002). According to Bohm $(1984,2002)$ they are abstractions from a deeper unity of nature in which it is implicitly acknowledged the inherent Wholeness of the Universe. That Wholeness can be never fully exhausted by science - science is even a part of that Wholeness - and that's why it demands from us stopping fixing our scientific theories and taking for granted that our insights must be seen as a never-ending process "with ever-changing form and content" (Bohm, 2002: 80). Accordiing to Bohm (2002) that Wholeness can only be perceived via the dynamicity of the notion of the Implicate Order of Nature. And even the Implicate Order of Nature should not be seen as a fixed, final or absolute theory about reality (Bohm, 2002). Besides, the laws of the Implicate Order are impenetrable by human understanding (Bohm, 2002) and that means that the Implicate Order is open to different approximations and interpretations.

\footnotetext{
${ }^{4}$ See also: Planck, M. (1998: 18, 20, 27), where Max Planck points out that "the scientific worldview is not something final" and "therefore the constant alternation (unfailing refinement) of the worldview does not denote a disruptive vacillation but a progress, an improvement, an accomplishment".

${ }^{5}$ See also: Heisenberg W. (1978: 38), where Heisenberg characteristically writes: "in natural sciences we are not interested about the universe as a whole, which includes even us, but how we steer our attention toward some defined parts of the universe and we set them as objects of our research".
} 


\section{Epistēmēs Metron Logos, Issue 4}

\section{Wholeness and the Implicate Order}

The sense of the Wholeness of reality leads us then to the Implicate Order which pervades that Wholeness in an inscrutable way. Quantum physics is acknowledged as the main evidence for that Implicate Order of nature (Bohm, 2002: 222, 234). In quantum physics we come to limited states of measurement where the discontinuity of movement becomes inevitable but not also fundamental, according to Bohm (2002). The discontinuity of movement in quantum physics is an abstraction from the continuity of the whole "flowing movement" of the Implicate Order (Bohm, 2002). Everything that we know as the ultimate elements and forces of nature are not but "projections" and "unfoldments" of the Implicate Order of nature in which the "wholeness of the flowing movement" is undivided and continuous (Bohm, 2002). Thus, the elementary particles for which Physics articulates knowledge today, and which are constantly increased in number with the advance of scientific research, do not constitute the ultimate reality of the Universe. The latter is pin-pointed and acknowledged by Bohm (2002) only in the Implicate Order of nature and its unknown laws. And the Implicate Order has unknown laws since our intellect, as a part of the wholeness of the Implicate Order and as a partial outcome of the laws governing the Implicate Order, cannot have knowledge of them (Bohm, 2002). Our intellect can just offer us implicitly the possibility to think that the wholeness of reality can never be exhausted by our understanding (Bohm, 2002).

The Implicate Order that pervades the Wholeness of the natural world might act deterministically and not probabilistically (Clegg, 2017: 89). The question of if Physics should acknowledge an Implicate Order causally determining the Universe is something that doesn't find the scientists in unanimity. ${ }^{6}$ In opposition to the dominant probabilistic interpretation of the Copenhagen cycle for the phenomena of quantum physics Bohm offers a reliable alternative view of a deterministically ordered universe (Clegg, 2017: 89). For Bohm (2002) the Universe which we see and in which we live is naturally unfolded from the interiority of a deeper undercurrent reality that he names "Implicate Order". The difficulty in the perception of the Implicate Order is our

\footnotetext{
${ }^{6}$ See: Michael Redhead (2006: 66) where Redhead points out the fact that: "contemporary physics has widely accepted the possibility of indeterminism [as for the quantum phenomena of the elementary particles]". It has to do with the prevailing probabilistic Copenhagen interpretation in Quantum Physics. The unavoidable indeterminism in Physics is again accepted by Stephen Hawking (2016: 63-64). Against the indeterminism stands the faith in the "deeper deterministic simplicity" that pervades the Universe and generates the "intricate and phenomenally random attitude [of the elementary particles]" (Polkinghorne, 1997: 99-100).
} 


\section{Epistēmēs Metron Logos, Issue 4}

persistence in the fragmentation, because of which we stray from the sense of the whole (Bohm, 2002). The elementary particles which Physics speaks of are not but "abstractions" and "projections" of that Implicate Order that deterministically produces all the wondrous multi-complexity of the natural world (Bohm, 2002).

The Implicate Order is the base of reality and she has not a definite form. In accuracy its form is totally unknown to us. We can feel it, but we can never totally or absolutely know it (Bohm, 2002: 226, 235). That is why the Wholeness that the Implicate Order indicates is something that is not susceptible to a final definition or a fixed, determined knowledge of how she really is (Bohm, 2002). The laws governing as Implicate Order the Wholeness of reality of the Universe can never be the content of human knowledge, as the very human knowledge itself is a production of that Wholeness (Bohm, 2002). Even the very notion of the "Implicate Order" should not be regarded as something fixed or final according to Bohm (2002) but just as a kind of perspective, a kind of looking at cosmos ant the wholeness of reality.

Bohm gives some intuitive perspectives of how we can perceive the Wholeness of the Universe via the Implicate Order that could unify it. The main feature of the Implicate Order is the "universal enfoldment" of all the phenomena that we perceive in the Universe as "unfoldment" of that universal enfoldment (Bohm, 2002). "Everything is enfolded into everything" inside the net of the Universe (Bohm, 2002: 225). This means that the nature of the Implicate Order is multidimensional and enables the inherent unity of all the elementary matter particles into a nexus of fundamental, but unknowable for man, deterministic and undivided junction. The multidimensional reality of the Implicate Order (Bohm, 2002: 240) surpasses the common perception of the quarto-dimensional spatiotemporal continuity, which modern Physics discusses after Einstein's Theory of General Relativity.

Inside that multidimensional reality the "universal flow of movement" pervades the Implicate Order of the Wholeness, generating the discontinuities of movement of the subatomic natural world with a rather fundamental ambiguity since the latter are considered as prime "abstractions" from the unaffected unity of the "universal flow of movement" (Bohm, 2002: 62-3, 237). That ambiguity does not, of course, refer to the very physical process of the quantized states of position and energy, but to our cognitive ability to analyze that physical process of quantum which reaches the limits of the infinitesimal in every attempt of ours to measure either the position or the momentum of the elementary particles (Heisenberg, 1978: 30. Gubser, 2017: 27-8). According to Heisenberg's principle of uncertainty, in which there cannot be concurrently and accurately defined position and momentum for a particle (Gubser, 2017: 25-6), this is mainly due to the grand velocities and energies that are observed 


\section{Epistēmēs Metron Logos, Issue 4}

in the range of the subatomic natural world. Each time scientists want to see, through their experimental research, what is exactly happening on that level they come up against the resistance of nature (Jeans, 1993). ${ }^{7}$ The measurement in that level is limited and finite, and can only lead us to the acknowledgment of the deeper deterministic simplicity ${ }^{8}$ which pervades the Implicate Order and remains unknown to us since it is far away from our measuring abilities (Bohm, 2002). The Implicate Order of Nature is that which, being cognitively impenetrable by the finite human intellect, constitutes the prime and fundamental reality of the natural world, the energetic structure of the whole Universe (Bohm, 2002). All the elementary particles of matter and force originate from that and all the wondrous complexity of nature is created from that.

Inside the Implicate Order the movement is as a consequence continuous and the laws governing its nature are unknown. To the contrary in the Explicate Order of quantum physics, namely in the scientific description and analysis of the fundamental phenomena of the subatomic natural world, the movement is non-continuous and the laws governing its operation are known, even though yet again not completely known (Bohm, 2002). That deficiency of the Explicate Order is what reveals for a cohesive Implicate Order (Bohm, 2002: 234); the former leads us to the acknowledgement of the latter. So we can continue by explaining how exactly the Explicate Order is associated with the Implicate Order of Nature. Through understanding Bohm's supposed relation of the two Orders, we shall attempt to articulate the reason of a fundamental metaphysics that is not directly named as such in Bohm's own work.

\footnotetext{
${ }^{7}$ Q. v. the idea of Heraclitus about the fundamental property of nature to love concealing its deeper reality. "Nature loves being hidden" Heraclitus says and that might be totally profound at the subatomic level of the natural world where our knowledge about what exactly is happening there confronts the majesty of the resistance of nature to our willingness to obtain a deeper and deeper access to its mysteries.

8 The idea of the "deeper deterministic simplicity" of nature can be found in Polkinghorne (1997: 99100) and can be seen as parallel to Bohm's notion of the Implicate Order (2002). Bohm believes in the deterministic action of the Implicate Order of nature, but he does not necessarily attribute to that action a form of simplicity since it might have an inconceivable complexity for the human understanding. Thus the question arrives: the deeper bedrock of the natural world is characterized by a form of simplicity or a form of intricacy? This is something rather unclear in Bohm's works. In the "Wholeness and the Implicate Order" the deeper bedrock of nature seems to be simple, a single origin of everything. But elsewhere, especially in his work "Causality and Chance in Modern Physics", the idea of the infinity of nature as a Wholeness might stand for an intricate account of the natural world (Bohm, 1984).
} 


\section{THE ACKNOWLEDGEMENT OF THE COGNITIVE LIMITS AND THE DYNAMICAL DIALECTIC OF PHYSICS AND METAPHYSICS}

\section{Implicate and Explicate Orders}

Until now we explained how the Implicate Order constitutes the deeper bedrock of the natural world from which the totality of the Universe is unfolded. But what is the Explicate Order to which Bohm refers? The Explicate Order is exactly that "unfoldment" of the Universe from the depths of the mysterious Implicate Order (Bohm, 2002). The Explicate Order is all that our senses can perceive in our interrelation with the natural world and at the same time all that we can know about the natural world through science in general (Bohm, 2002). Our senses are far too more limited than the heightened experimental measuring instruments of the scientific laboratories (Jeans, 1993). Therefore whatever we are able to know about the Universe through Physics constitutes the Explicate Order of the Universe.

The Explicate Order has a relative degree of autonomy from the Implicate Order from which it inherently originates (Bohm, 2002: 226). The Implicate Order is not knowable by man, which is in opposition to the partial knowledge that the Explicate Order allows us to reveal pertaining to Physics (Bohm, 2002). As Bohm put it, the Implicate Order is "universal and primary" whereas the Explicate Order is "derivative and secondary" and thus, appropriate for providing us with knowledge about the Universe "only in certain limited contexts" (Bohm, 2002: 235). All the partial and specific theories of Physics are what constitute the analyzability that characterizes the Explicate Order. Classical Mechanics, Quantum Physics, the theory of Relativity are all "certain limited contexts" in which our knowledge about the Universe is analyzed through the mathematical, experimental and theoretical method (Bohm, 2002). Each physical theory is valid in the context that it is practiced in, and in the limits that that context imposes to it (Bohm, 1984, 2002). The Explicate Order can thus be seen as a specific, limited state of the universal Implicate Order.

The sub-totalities of the Explicate Order - a sample of which we cited above - are generated by the universal Wholeness of the Implicate Order and as a result the knowledge that they give to us is neither final nor absolute (Bohm, 2002: 226). Only the Implicate Order involves the real depths of Nature and even this should not be seen as something final or absolute (Bohm, 2002: 270-1). The scientific descriptions of the Universe which constitutes the analyzability of the Explicate Order have only a relative autonomy and provide limited knowledge about the world in which we live. 


\section{Epistēmēs Metron Logos, Issue 4}

What characterizes the descriptions given by the Explicate Order is the fact that they are systems of repeatability in which can be found "recurrent and relatively stable elements that are outside of each other" (Bohm, 2002: 226). Those elements are the particles and the fields which contemporary Physics speaks about and which constitutes the mechanistic view of nature (Bohm, 2002). Both the particle and the field theory of matter and force have a specific relative autonomy and complementarity between them (Heisenberg, 1978: 27, 34-5). Nevertheless, both of them constitute "abstractions" from the undivided nature of the Implicate Order in the depths of which the ultimate nature of matter and force remains unknown and unknowable (Bohm, 2002: 226). In the dominant mechanistic view of the Universe the elementary particles and the fields are perceived as constituents of the basic reality. But under the aspect of the Implicate Order the elementary particles are just "abstractions" that appear and occur in our knowledge about the natural world (Bohm, 2002: 233-4). The outward stability of their existence probably deceives us that they indeed constitute the "basic building blocks of nature" (Hawking, 2016: 74-5), but we ought to acknowledge just their relative autonomy over the Implicate Order that federates and unites the Universe (Bohm, 2002). In other words the elementary particles do not constitute the ultimate nature of matter and force.

Bohm describes with three equal definitions the elementary particles, the fields and the usual view of space and time in modern Physics as well: "abstractions", "projections" and "unfoldments" (Bohm, 1984, 2002). With the use of that terminology he makes clear the fact that all our scientific knowledge about the natural world is not but fragmentary and limited. The limits of the descriptions given by the Explicate Order coincide with the limits of our knowledge about the Universe. Of course those limits are not absolute concerning the objectivity of the world. Through their acknowledgement we are led to the perception of the "undivided Wholeness of the Universe" and the Implicate Order that pervades it. We realize that the Whole is not exhausted by the parts (Redhead, 2006: 51, 60-1) and that the Whole should always be open to ever-changing forms of insights that try to define it (Bohm, 2002).

\section{The universal enfoldment inside the Implicate Order: relation of matter and intellect.}

That mysterious nature of the Implicate Order is what can raise metaphysical pretensions in Bohm's system of description of the Universe. Everything resides in the Implicate Order in the form of enfoldment (Bohm, 2002: 225). Actually that enfoldment of reality that lies inside the Implicate Order is governed by different grades and "various phases in different stages of enfoldment" (Bohm, 2002: 258). 


\section{Epistēmēs Metron Logos, Issue 4}

Inside the Implicate Order is acknowledged the deeper reality of nature which is the "undivided Wholeness of the Universe" (Bohm, 2002: 227). In that Wholeness the enfoldments of elements of the reality generate the unfoldments of the reality in "inanimate matter", "life forms" and "consciousness" (Bohm, 2002: 246-7, 249-250). Life, energy, matter and mind are all united in the Wholeness of the Implicate Order where the universal enfoldment of the unknown causes generating their distinct forms really dominates (Bohm, 2002). The universal enfoldment resides inside the "common higher-dimensional ground" of the whole Universe (Bohm, 2002: 266). This "common higher-dimensional ground" constitutes the single origin of everything, and everything means: forms of energy, matter, life, mind and consciousness (Bohm, 2002).

The Universe is governed by a fundamental unity according to Bohm and that is why man can be aware of himself as a part of that universal unity (Bohm, 2002: 264-7). ${ }^{9}$ The notion of the Cosmic Heritage that joins us and links us with the Universe is rather a recent achievement in the history of Physics (Field \& Chaisson, 2014: 198). Man shares together with the whole Universe the common descent of a "single totality" that acts as Implicate Order (Bohm, 2002: 266). In that single origin of everything matter and mind find their common base. The special monism that Bohm appears to promote in his work "Wholeness and The Implicate Order" concerning the relation of matter and mind could be named as "monism of dualist character". The "monism of dualist character" avoids the reductive attribution of matter to mind or of mind to matter, thus promoting the faith in an independent but common base of both (Polkinghorne, 1997: 84-5). Therefore the dualist monism of matter and intellect is grounded in the assumption of the "common ground" (Bohm, 2002: 250, 265) that resides in the depths of the Implicate Order of the Universe. Inside the "higher-dimensional ground" of the Implicate Order "mind and body are ultimately one" (Bohm, 2002: 265). That "common ground" of the Implicate Order from which everything is generated is something that surpasses the nature of both the matter and the intellect (Bohm, 2002: 265). "This ground is what is primary, self-existent and universal" (Bohm, 2002: 247) and the depths of its inwardness are totally unknown to us (Bohm, 2002: 267).

\section{Implicate Order and Theory of Everything.}

Under the aspect of that fundamental ignorance that covers the Implicate Order of Nature, it could be tested how far a Theory of Everything in contemporary Physics

\footnotetext{
${ }^{9}$ Q. v. Spinoza's notion of unity of the metaphysical monism under the aspect of which man is regarded as a finite part of the infinite "God or Nature" - the primordial and the only one substance of the universe. Spinoza's "God or Nature" is the ultimate One of the Reality by which all the many things of the whole natural world are causally produced.
} 


\section{Epistēmēs Metron Logos, Issue 4}

could be epistemologically acceptable. In this crucial point, it seems that Physics and Metaphysics are perplexed equally dynamically with the question of matter to intellect relation. The formulation of a Theory of Everything constitutes the absolute vision of physicists (Theodosiou, 2008). The aim of such a theory is to unite the disparate physical theories and fundamental forces of nature into a single cohesive unity, able to provide the fundamental knowledge of the ultimate structure of matter and force (Theodosiou, 2008).

Until now physicists have commonly accepted the so-called "Standard Model" of the elementary particles of matter and force (Hawking \& Mlodinow, 2011). It is the physicists' vision to reduce into a single theory the two great theories of $20^{\text {th }}$ century Physics: Quantum Mechanics (subatomic natural world) and the Theory of Relativity (gravity and space-time), such that each of the two still has its own autonomy (Hawking \& Mlodinow, 2011). The Superstring theory is the rather contemporary candidate for such a union (Theodosiou, 2008). It is a "high promising theory" since it can conjoin the quanta of matter and energy with the field vision of natural forces in the universe into a single interpreting account (Gubser, 2017: 9-10). The Superstring theory provides a tentative vision about how all the natural forces can be described, offers unity in the nature of the elementary particles, since all of them are seen as differently vibrating strings, and speaks about ten dimensions, since the vibration of the strings is located, for many technical and mathematical reasons, on a multidimensional reality of a super-symmetrical state (Gubser, 2017. Theodosiou, 2008). The mathematics that describe it are too bizarre so as to fulfill the needs of the pursued super-symmetry (Gubser, 2017). Nevertheless the Superstring theory has not been yet experimentally tested and thus the question remains open and it might remain such for many years (Gubser, 2017. Kaku, 2016).

A Theory of Everything may not be accepted epistemologically, since the deep laws governing the Implicate Order are unknown to man. In accuracy, a Theory of Everything in the way Physics desires it, cannot be identified with the absolute knowledge of the ultimate nature of reality. Perhaps, it might have a unified interpreting strength in the exegesis of the Universe, but again it seems that it is judged as abstractive in front of the acknowledgement of the Implicate Order, considering that it cannot exhaust the unknown laws that govern the latter. Bohm lived and wrote in an era in which there was a high interest in the pursuit of a Theory of Everything. ${ }^{10}$ However, in his work "Wholeness and the Implicate Order" faith in such a theory

${ }^{10}$ Since 1984 and afterwards (that means four years after the first publication of the work "Wholeness and The Implicate Order" in 1980) the String Theory, with its unifying power and its reference to the multidimensional nature of reality, started being acknowledged as a viable candidate theory about the 


\section{Epistēmēs Metron Logos, Issue 4}

is not promoted. Contrariwise, it is pinpointed that any given scientific vision of the Universe is inherently impotent, while humane, to get access to an absolute knowledge of reality (Bohm, 2002).

\section{The depths of the Implicate Order as the "common ground" of the whole Universe and the question of God}

Bohm sets inside the unknown depths of the Implicate Order, except for matter, life, mind and consciousness. This way it cannot be everything reduced to the ultimate nature of matter since even that one (if it really is one) is hidden inside the Implicate Order and it does not exhaust the reality of the Universe. The "common ground" of the whole Universe - which acts as a single origin of everything - is neither the matter nor the intellect; it is something beyond both of them, which are generated by that (Bohm, 2002). In a way energy could be the primary candidate for that "common ground" inside the Universe (Bohm, 2002. Heisenberg, 1987), but again in Bohm's thought the Implicate Order is totally unknown and unanalyzable (Bohm, 2002).

We say that energy could be the primary candidate for the "common ground" because Bohm speaks about the "immense ocean of cosmic energy" from which our Universe could be born as a "sudden wave pulse" (Bohm, 2002: 244). The nature of the Implicate Order is thus energetic and that might mean that energy constitutes the common background of the whole Universe. Nevertheless, the universal enfoldment of everything - which is inside the depths of the Implicate Order - seems to affirm a single origin of everything, the nature of which could not be seen as a totally known form of energy. Therefore a problem arises: is energy the ultimate nature of everything or not? Is there any ultimate nature of energy which could be seen as the single origin of everything? In my personal view I think that according to Bohm there is not such an ultimate nature of energy since the Implicate Order, even if it is energetic, is unknown to man and it should not be seen as a final or ultimate stage of truth and reality (Bohm, 2002: 270). But if this "common ground" should not be seen as a final or ultimate stage of reality then how does Bohm say that it is "self-existent" (Bohm, 2002: 247)? Could it not be a divine creation in its deeper roots? Perhaps Bohm defines

description of the Universe in its ultimate nature and thus started gaining more and more ground among physicists from then on (Gubser, 2017). It is worthy to think about what attitude Bohm would have towards the Superstring Theory. My personal view is that he would acknowledge its power and its success but only inside the limits of it being an Explicate-Order description. Thus, he would acknowledge its interpretive power only at the level of abstractive analysis. Superstring Theory would be probably judged by him as another abstraction from the unknown and unanalyzable Implicate Order of the Universe (Bohm, 2002) or the infinite Wholeness of Nature (Bohm, 1984). 


\section{Epistēmēs Metron Logos, Issue 4}

the "common ground" as "self-existent" only in comparison with the "sub-totalities" of matter and mind. But this is just a proposal.

If the Implicate Order of the Universe could be seen as a work of a transcendent God, then it could really constitute the deeper background of reality and offer unity in the Universe from the very beginning and by default. The Universe could be a divine creation that, as a vast living organism, started from the unknown creating power of God and continued its development according to that power which God set inside it from the very beginning (Polkinghorne, 1997: 107, 125-6, 149). The parameter of God is not included in Bohm's work, howbeit is not even excluded. Someone could assert that since the "common ground" is "self-existent" (Bohm, 2002: 247) then a place for God is surely excluded. But, in my personal view, since even that "common ground" should not be seen as an "absolute end of everything" (Bohm, 2002: 270) then a place for God is not excluded at all. Howbeit, the problem remains: if the "common ground" is "self-existent" how is it not at the same time the "absolute end of everything"? Since we cannot define the final truth (Bohm, 2002: 270-1) how can we then assert with final certainty that the "common ground" is "self-existent" or not? I think that the response in this question should not be a fixed assertion as this attitude best suits Bohm's vision about truth and reality. What becomes really clear according to Bohm (Bohm \& Hiley, 1993. Bohm, 2002) is that we should acknowledge the fundamental, ontological unity of the Universe feeling ourselves and our existence as a part of that unified whole.

\section{AFTERWORD}

Arriving here I hope that the promise given in the beginning is finally met with success and the originality and the depth of Bohm's thought about the nature of reality to be clearly featured. We explained how the notion of the Implicate Order is acknowledged as essential for the conception of the "undivided Wholeness of the Universe". We saw that the Explicate Order of reality (which Physics as a form of science speaks about) is perceptible and knowable for man, whereas the Implicate Order of reality (which Physics is unable to give even the humblest description of) is inherently unseen and unknown for all of us.

It's time to confess the fact that Explicate and Implicate Orders are both intertwined into a non-dissolvable, cognitive wholeness in which is affirmed knowledge and ignorance. The Explicate Order of nature authorizes us always to have a limited access to the knowledge of the Universe, while the Implicate Order, being invisible and mysterious, keeps us in absolute ignorance of how or what exactly it is (Bohm, 2002). In the fragmentation and abstraction of the Explicate Order, the knowledge that Physics as a form of science is able to offer us does not stop being knowledge, but it 


\section{Epistēmēs Metron Logos, Issue 4}

is deprived of the privilege to claim being an absolute knowledge. In the acknowledgement of the Implicate Order that unites the Universe man realizes the limits of his knowledge and so his ignorance about the deeper nature of reality. Human knowledge is an output, a part of the Wholeness of the Implicate Order and hence it cannot scientifically analyze its descent to that Wholeness, it can only implicitly intuit it (Bohm, 2002).

Man seems standing inside a fundamentally ignoring knowledge. While he can partly know the reality he inherently is in a clear ignorance about the deeper nature of reality. In the context of experiencing of that fundamentally ignoring knowledge man can recognize the deep complexity of Physics and Metaphysics the way this one is featured by a fruitful and endless dialectic between the known that the former provides and the unknown that the latter affirms.

The presentation of Bohm's theory about the "undivided Wholeness of the Universe" today, I believe, it is rather a lofty attempted reminder of the fundamental Metaphysics or "quasi-Metaphysics" that unavoidably arrives at the forefront each time man hankers after obtaining a deeper knowledge of the reality of the natural world. The reality of the Universe is a reality of Wholeness (Bohm, 2002) in which man realizes his partiality and the imperfection of his knowledge. Speaking about the unknown nature of the Wholeness is nothing more than defining the full scope of the appearance and the reappearance of Metaphysics in our thought. I speculate that the notion of the Implicate Order cannot but constitute a forceful voice over the metaphysical philosophy in opposition to the notion of the Explicate Order that is constantly analyzed by the science of Physics.

As soon as man realizes his ignorance about the deeper nature of reality he is able to cultivate a sense of humility and admiration in front of the Universe (Planck, 1998). Feeling his common descent with the whole natural world he can live out his unity with the Universe through the acknowledgement of the Implicate Order as the matrix of that common descent of everything. Bohm's vision about the realization of that fundamental unity of man and Universe reminds us of something from Spinoza's vision about the unity of the metaphysical monism. Reality is the One of the Wholeness.

If this One of the Wholeness is a final or an absolute stage of the real this is something that we will never be able to answer with accuracy and certainty (Bohm, 2002: 270-1). And maybe here the value of our intellectual life inside the Universe can be found. Only we are those who direct questions at that one and about that one. The answers that we receive satisfy us only unto a small grade. Maybe finally we are indeed led through Physics to the really ultimate which, according to Max Planck 


\section{Epistēmēs Metron Logos, Issue 4}

(1998), is nothing else than the existence of God. Perhaps God is the ultimate truth (Polkinghorne, 1997). But in any case, that which we should do according to Bohm $(1984,2002)$ is to be alerted and forewarned of the pretensions of our knowledge. We are a part of the Universe and our knowledge about it is really limited. Nevertheless, this is not enough to distract us from our deep desire to come closer to the reality in its ultimate and more perfect form (Hawking, 2016). The deep understanding of our existence and the existence of our world is something that is going to steadily and constantly lead our cognitive power in its limits.

\section{REFERENCES}

Bohm, D. (1984). Causality and Chance in Modern Physics. London and New York: Routledge and Kegan Paul Ltd, first published in 1957.

Bohm, D. (2002). Wholeness and The Implicate Order. $2^{\text {nd }}$ ed. London and New York: Routledge Classics, first published in 1980.

Bohm, D. \& Hiley, B. J. (1993). The Undivided Universe: An ontological interpretation of quantum theory. London and New York: Routledge.

Clegg, B. (2017). 30-second Quantum Theory, the 50 most important thoughtprovoking quantum concepts, each explained in half a minute. London: Icon Books, Ivy Press.

Dear, P. (2007). The Intelligibility of Nature: How science makes sense of the world. Chicago and London: University of Chicago Press, first published in 2006.

Field, G. B. \& Chaisson, E. J. (2014). The Invisible Universe. Heraklion: Editions of the University of Crete (edition in Greek language), first published in 1995.

Gubser, S. S. (2017). The Little Book of String Theory. Heraklion: Editions of the University of Crete (edition in Greek language), first published in 2010 by Princeton University Press.

Hawking, S. (2016). A Brief History of Time: from Big Bang to Black Holes. $6^{\text {th }}$ ed. London: Bantam Press, first published in 1988. 


\section{Epistēmēs Metron Logos, Issue 4}

Hawking, S. \& Mlodinow, L. (2011). The Grand Design, New answers to the ultimate questions of life. London: Bantam Press, first published in 2010.

Heisenberg, W. (1978). Physics and Philosophy. Athens: Kalvos Editions (edition in Greek language), first published in 1959.

Jeans, Sir J. (1993). Physics and Philosophy. Thessaloniki: Vanias Editions (edition in Greek language), first published in 1981.

Kaku, M. (2016). Hyperspace: a scientific odyssey through parallel universes, time warps, and the tenth dimension. Oxford and New York: Oxford University Press.

Nilsson, N. J. (2014). Understanding Beliefs. Cambridge, Massachusetts: MIT Press.

Planck, M. (1998). Sinn und Grenzen der exakten Wissenschaft, Mit einem Nachwort herausgegeben von Fritz Kraft. Thessaloniki: University Studio Press (edition in Greek language), first published in 1952.

Polkinghorne, J. (1997). Beyond Science. Athens: P. Travlos - E. Kostaraki Editions (edition in Greek language), first published in 1996 by Cambridge University Press.

Redhead, M. (2006). From Physics to Metaphysics. Heraklion: Editions of the University of Crete (edition in Greek language), first published in 1995 by Cambridge University Press.

Theodosiou, S. (2008). Philosophy of Physics: from Descartes to the Theory of Everything. Athens: Diavlos Editions (edition only in Greek language). 